\title{
Actinomycetes: A Promising Tool for Plant Growth Promotion and Disease Control
}

\author{
Nanjappan Karthikeyan ${ }^{1}$, Kuppusamy $\operatorname{Pandiyan}^{1}{ }^{*}, \operatorname{Pramod}_{\text {Kumar Sahu }}{ }^{1}$, \\ Ramakrishnan Srinivasan ${ }^{2}$ and Udai B. Singh ${ }^{1}$
}

${ }^{1}$ ICAR-National Bureau of Agriculturally Important Microorganisms, Mau, UP, India

${ }^{2}$ ICAR-Indian Grassland and Fodder Research Institute, Jhansi, UP, India

*Corresponding author

\section{A B S T R A C T}

\section{Keywords}

Actinomycetes,

Plant growth

promotion,

Biocontrol,

Endophytic

Article Info

Accepted:

17 June 2018

Available Online:

10 July 2018
Plant growth promotion and biological control without deteriorating the environment and soil for sustainable agriculture has necessitated the exploration for microbial resources to replace the agrochemicals and fertilizers. Bacteria and fungi are widely distributed in the biosphere including the rhizosphere and help the plants by alleviating biotic and abiotic stress through diverse mechanisms and can be developed as bioinoculants for biocontrol and plant growth promoting activities. Actinomycetes are one of the most abundant group of soil microorganisms and well known for their antibiotics production to control the microorganisms. They are well studied for their role in biological control of plant pathogens, interactions with plants and plant growth promotion. This review briefly summarizes the effects of actinomycetes on biocontrol, plant growth promotion and association with plants as endophytes.

\section{Introduction}

Green revolution in India made a paradigm shift in agriculture from being a food grain importer to an exporter. This was achieved by consuming huge amount of chemical pesticides and fertilizers which was initially boosted the agricultural yields but became stagnant in the later years. This intensive use of chemical pesticides not only resulted in deterioration of soil health but also affected adversely the microbial diversity and population in the soil. In recent years, there is growing concern towards the utilization of microbial inoculants as a replacement for the chemical pesticides and fertilizers for achieving the sustainable agriculture. In this perspective, microorganisms with the potential of producing plant growth-promoting substances, antimicrobial compounds seem to be the better alternative to the chemicals (Dhanasekaran et al., 2005). Actinomycetes are Gram-positive, aerobic, filamentous bacteria present in diverse ecological niche such as soil fresh water, back water, lakes, compost, marine environment etc. As most of them are filamentous and sporulating in nature they strongly adhere to the soil particles and 
establish intimate contact (endophytic association) with the plants (Cao et al., 2004). They grow abundantly in soil with rich in organic matter and composing approximately $10 \%-50 \%$ of the soil microflora community over a broad range of soil types and conditions.

The genus, Streptomyces, is the largest representative of actinomycetes, as it comprises huge number of species and varieties producing the majority of known antibiotics. Besides acting as agent for organic matter decomposition, actinomycetes play a vital role in control of plant pathogens (Hoster et al., 2005) and plant growth promotion (Nassar et al., 2003). This is due to their capability to act and exhibit production of antibiotics, siderophores, antimicrobial enzymes, plant growth promoting substances, phosphate solubilization, and competition with plant pathogens for food and space. The PGP microbes provide the additional benefit of being a biofungicides with inorganic or as a replacement to manage the fungicide resistance among plant pathogens and to reduce the number of fungicide applications per year (Gopalakrishnan et al., 2013) which may otherwise cause serious deterioration of soil health.

The role of actinomycetes in the plant growth promotion like siderophore production, indole acetic acid (IAA) production, P-solubilization and biocontrol activity against various pathogens such as Fusarium sp. (Lu et al., 2008; Gopalakrishnan et al., 2013; Sreevidya et al., 2016), Rhizoctonia sp. (Goudjal et al., 2014), Pythium sp. (Hamdali et al., 2008), Sclerotium sp. (Prapagdee et al., 2008; Pattanapipitsai and Kamlandharn, 2012) and Colletotrichum sp. (Prapagdee et al., 2008; Palaniyandi et al., 2011) have been reported. Further, they also exhibit an endophytic association with the plant and benefits for growth and development of the host. These properties of actinomycetes make them suitable bio-inoculant for the sustainable agriculture and soil health improvement.

\section{Role in plant growth promotion}

\section{Plant growth regulators}

Plant growth promoting (PGP) microbes are rhizosphere associated organisms that colonize the rhizosphere and rhizoplane which enhances the plant growth when artificially inoculated into the soil directly or through seed coating (Gopalakrishnan et al., 2013\& 2015). Root exudates play a vital role in PGP as being a major source for natural tryptophan, which may enhance the microbial biosynthesis of IAA and other auxins in rhizosphere region (Khamna et al., 2009). Many endophytic as well as rhizospheric actinobacteria possess the ability to produce IAA, cytokinins and $\mathrm{GA}_{3}$ (El-Tarabily and Sivasithamparam, 2006; Vijayabharathi et al., 2016). Nimnoi et al., (2010) reported the production of indole3 -acetic acid (IAA) and ammonia, a trait of plant growth promotion by endophytic actinomycetes from eaglewood (Aquilaria crassna). These isolates were found producing different types of siderophores and protease as biocontrol agents. The siderophores secreted by microbes increase the iron supply to plants and microbes; in addition to that they also inhibit the growth of plant pathogens. Hence, IAA and siderophore producing actinomycetes that colonize the root in the rhizosphere are known to promote the root elongation and plant growth (Khamna et al., 2009; ElTarabily et al., 2009; Sreevidya et al., 2016). They also benefit the plant by increasing the availability of trace elements such as iron, zinc etc., in the rhizosphere (Cakmakci et al., 2006). Gopalakrishnan et al., (2013) evaluated five strains of Streptomyces sp. which were proved as biocontrol agent against $F$. oxysporum f.sp. ciceri (Gopalakrishnan et al., 2011) in green house and field for their plant 
growth promoting ability in sorghum and rice. Several endophytic actinobacteria including Streptomyces viridis, $S$. rimosus, $S$. olivaceoviridis, S. atrovirens and S. rochei exhibited improved germination as well as root and shoot elongation (Abdallah et al., 2013).

\section{P-solubilization}

Phosphorus is an important element for the plant growth and agricultural yields and the availability of soluble $\mathrm{N}$ and $\mathrm{P}$ nutrients are often limiting in agricultural soils due to the extensive cropping pattern and they are supplemented as chemical fertilizers. Though the soluble chemical fertilizers are readily available to the plants, most of them (70-80\%) are quickly immobilized in soil and washed away by the raining waters, ground waters and make them unavailable for the plant growth (Shigaki et al., 2006). This indulges the farmers to repeatedly amend their fields with these chemical fertilizers that pose a threat for human life as well as environment which urges the replacement of this expensive soluble chemical $\mathrm{P}$ by novel, cheaper and more environment friendly but nevertheless be a efficient $\mathrm{P}$ fertilizers.

The natural rock phosphate (RP) seems to be a promising alternative source of $\mathrm{P}$ fertilizers if a natural and non-polluting mechanism for its solubilization is found. Several microorganisms generally known as phosphate solubilizing microorganisms (PSM) have been reported to solubilize RP by using different strategies that include acidification, ion chelation or ion exchange. Among the PSM, the strains of Pseudomonas and Bacillus are the most powerful phosphate solubilizing bacteria. In addition to that, actinomycetes are of special interest since these filamentous bacteria are capable of forming colonization in the root tissue and producing spores for its survival in the agricultural soil and play a key role by releasing a soluble phosphate from insoluble rock phosphate (Hamdali et al., 2008). Various genera of actinomycetes such as Rhodococcus, Arthrobacter, Streptomyces, Gordonia and Micromonospora were reported to have P-solubilization potential under laboratory and glasshouse conditions (Jog et al., 2014). Under P-deficient soils, Streptomyces griseus, Streptomyces spp, Micromonospora aurantiaceae performed in terms of P-solubilisation under wheat crop (Hamdali et al., 2008; Jog et al., 2014). Productions of various organic acids such as gluconic acid, citric acid, malic acid, lactic acid, propionic acid, oxalic and succinic acids by actinomycetes are believed to be the mechanism of their phosphate solubilization (Hamdali et al., 2010; Jog et al., 2014). The root exudates represent the major source of nutrients, such as carbohydrates, organic acids, amino acids and they influence the diversity of phosphate solubilizing microbes and their capacity with respect to different rhizosphere of plant.

\section{Actinomycetes in plant-AM fungal and plant-rhizobioum association}

The Arbuscular Mycorrhiza (AM) fungi represent the key group of soil-borne microbes and known to play an important role in agriculture sustainability. Mycorrihza, a symbiotic relationship between plant roots and fungi, is a dominating plant symbiosis in terrestrial ecosystem and helps in nutrient uptake by the plants. The formation of mycorrhizal symbiosis is promoted by socalled "mycorrhization helper bacteria (MHB)" (Garbaye et al., 1994) and the possible mechanism underlying the helper effect is the direct effect exerted on mycorrhizal fungi for their pre-symbiotic survival and growth in the soil (Frey-Klett et al., 2007). Inoculation of actinomycetes has significant effect on the enhancement of mycorrizal colonization. It has been observed 
that the occurrence of mycorrhizal colonization and formation of arbuscules, the nutrient transfer site, were significantly higher in roots of plants grown in soil inoculated with Streptomyces coelicolor compared with untreated mycorrhizal plants (Abdel-Fattah and Mohamedin, 2000). Inoculation of Streptomyces sp. has significantly promoted mycelial extension, growth and mycorrhization rate of Amanita muscaria in spruce, Suillus bovines in pine and Glomus mosseae in cloves (Schrey et al., 2005; Franco-Correa et al., 2010). The compatibility of inoculated actinomycetes with survival, formation and functioning of AM symbiosis has receive keen interest among researchers and it has been found that certain Streptomycetes capable of producing antimicrobial compounds (El-Tarabily and Sivasithamparam, 2006) do not exhibit inhibitory effects on AM fungi, but some others reported to be inhibitory.

Actinobacteria when co-inoculated with nitrogen fixing organisms such as Rhizobium, Bradyrhizobium, Mesorhizobium, Sinorhizobium has shown improved nodulation and nitrogen fixation by the $\mathrm{N}_{2}$ fixing organism. Streptomyces, Actinoplanes and Micromonospora are the promising actinobacteria for the role of helper bacterial (Gregor et al., 2003; Solans et al., 2009; 2015). Studies conducted by Soe and Yamakawa (2013) showed that the coinoculation of Streptomyces griseoflavus P4 and Bradyrhizobium yuanmingense MAS34 on soybean resulted in enhanced nodulation, nitrogen fixation and seed in various varieties of soybean. This result emphasizes the importance of inoculation of actinobacteria with nitrogen fixers in leguminous crops.

\section{Role in disease control}

The plant system possesses its own resistance mechanism against plant pathogens but the rhizosphere microorganisms contribute to this resistance additionally by excreting substances or metabolites limiting the growth of phytopathogenic fungi or by stimulating natural defense mechanism of the plant (Lehr et al., 2008).

A greenhouse investigation was carried out with three endophytic actinomycetes Actinoplanes campanulatus, Micromonospora chalcea and Streptomyces spiralis for their potential to promote plant growth and to protect cucumber from pathogen Pythium aphanidermatum causing damping-off, crown and root rot. It can be used in the nutrient poor soils for crop production as it has good potential to perform as plant growth promoter. As a mechanism of plant growth promotion these organisms found producing plant growth regulators i.e. auxins indole-3-acetic acid (IAA) and indole-3-pyruvic acid (IPYA), gibberellic acid (GA3) and cytokinins isopentenyl adenine (iPa) and isopentenyl adenosine (iPA). These three endophytic isolates screened on the basis of their ability to produce $\beta-1,3, \beta-1,4$ and $\beta-1,6$-glucanases to antagonize $P$. aphanidermatum. These endophytes found producing glucanase especially in a consortial treatment which can be used in place of metalaxyl, a fungicide recommended for Pythium diseases in the area Consortium of these three was proven better for plant growth promotion and biocontrol as compared to the respective individuals (ElTarabily et al., 2009).

Many workers have been reporting the biocontrol activities of endophytic actinomycetes by secretion of antimicrobials, enzymes, competition for food, etc. establishing a thrust area of research. Dhansekaran et al., (2005) mentioned several mechanisms of endophytic actinomycetes to protect the plant which involves the production of antifungal compounds, chitinolytic activities and competition for 
nutrients through siderophore production. Antibiosis is likely to be the important mechanism for biocontrol activity of actinomycetes as most of the isolates which shown antagonism in-vitro was also shown its effect in vivo (Trejo-Estrads et al., 1998).

Verma et al., (2009) isolated endophytic actinomycetes from neem (Azadirachta indica). Most common genus found was Streptomyces. Few other genus isolated were belong to Streptosporangium, Microbispora, Streptoverticillium, Sacchromonospora and Nocardia were also isolated. These isolates had shown antagonistic activity against root pathogens Pythium and Phytophthora sp. and can be developed into biocontrol agents against these fungal pathogens.

Rice endophytes were examined for their biocontrol potential by Tian et al., (2004). Biocontrol potential of endophytic fungi and actinomycetes were assessed. In dual culture with pathogens, $41.2 \%$ of endophytic fungi and $50 \%$ of endophytic actinomycetes were found antagonistic to fungal pathogens. The major genera in endophytic actinomycetes were found to be Streptomyces griseofuscus and hygroscopicus. More diversity of endophytic actinomycetes was found in roots of rice plant and in alkaline soil.

Antimicrobial activity of endophytic actinomycetes was also studied in Rhododendron (Shimizu et al., 2000) and found effective against Gram-positive bacteria, yeast and filamentous fungi. Cao et al., (2004) deciphered biocontrol activity of endophytic actinomycetes against panama wilt of banana. Few of the strains, like Streptomyces griseorubiginosus were described as potential biocontrol agents against panama wilt pathogen Fusarium oxysporum f. sp.cubense. Siderophoreproducing Streptomyces endophytes were suggested as biological control agent of fusarium wilt of banana (Cao et al., 2004). Tan et al., (2006) assessed the biocontrol potential of endophytic actinomycetes against bacterial wilt of tomato caused by Ralstonia solanacearum and tested different isolates for their potential for production of siderophores. It is a serious pathogen of tomato and very difficult to control. In such cases use of endophytic actinomycetes may be a better candidate as biocontrol agent.

\section{Production of antimicrobials}

Actinomycetes are abundant producers of antibiotics, which produces about $45 \%$ of the total antibiotics currently in use and they produces diverse natural products that would be approx. 10,000 compounds (Liu et al., 2012). In soil, the production of antibiotic metabolites (Hyang et al., 2005) and antimicrobial compounds (Sabaratnam and Traquair, 2002; Lehman et al., 2005) facilitate actinomycetes to restrict the invasion of plant pathogens to the habitats. The structure of the active metabolite from Nocardia levis MKVL_113 was elucidated using ${ }^{1} \mathrm{H}$ NMR and ${ }^{13} \mathrm{C}$ NMR spectra and identified as 1phenylbut-3-ene-2-ol which was reported first time as a natural product (Kavitha et al., 2010). In the study of Streptomyces lydicus strain A01, the main antifungal compound (antagonist to Fusarium oxysporum, Botrytis cinerea, Monilinia laxa etc.) was obtained using column chromatography and HPLC. Further, the structural analysis revealed that the produced compound is natamycin, a potential polyene antibiotic widely used as a natural bio-preservative for food ( $\mathrm{Lu}$ et al., 2008).

Streptomyces sp. is the most widely studied biocontrol agent among actinomycetes and they have the essential characteristics that make them suitable as a biocontrol agent against soil borne pathogens. Streptomycin and cycloheximide are the first antibiotics 
applied for the control of fungal and bacterial pathogens in plants, which are produced by Streptomyces griseus. The potential to produce multiple antibiotics or a antibiotic with diverse mechanism by the biocontrol agent is desirable for the suppression of diverse pathogenic microbes. Further, the antibiotics of actinomycetes have application as a broad range soil fungicide alternative to the use of chemical fungicides such as methyl bromide and metalaxyl (Jinhua et al., 2010). Azalomycin, an antibiotic, when treated with soil as culture filtrate resulted in more than $80 \%$ decrease in fungal population after 14 days of treatment and found to be stable over a broad range of $\mathrm{pH}$ and temperatre and exhibited antagonism against Fusarium oxysporum, Rhizoctonia solani, Sladosporium cladosporioides, F. chlamydosporum, Alternaria solani and Colletotrichum gloeosporioides (Jinhua et al., 2010). Few of the isolates from medicinal plants of Panxi plateau in China were found to harbour genes for antibiotics production. PCR amplification for genes coding for polyketide synthetase (PKS-I, PKS-II) and nonribosomal peptide synthetase (NRPS) exhibited broad-spectrum antimicrobial activity of endophytic actinomycetes. Predominant genera were Streptomyces, while the remainder belonged to genera Micromonospora, Oerskovia, Nonomurea, Promicromonospora and Rhodococcus (Zhao et al., 2011).

Sreevidya et al., (2016) reported the antagonistic effect of actinomycetes that were isolated from vermicompost and soils against Macrophomina phaseolina and Sclerotioum rolfsii in chickpea crop. Similarly, the antagonistic activity of actinomycetes from wheat Rhizosphere was shown by Jog et al., (2014). The main mechanism involved in biocontrol of pathogens are secretion of bioactive compounds such as antibiotics and cell wall degrading enzymes, competition for space and nutrients, mycoparasitism and induction of plant defensive mechanism (Bakker et al., 2007). Endophytic actinomycetes are being reported continuously as potential agent for secreting novel antimicrobial compounds. The use of endophyte actinomycetes as a potential biocontrol agent is having great possibility as they can colonize interior of the host plant avoiding competition by the other microbes. The establishment of natural regeneration from seeds to uniformly grown plants under harsh conditions indicates the contribution of endophytic microbes for the bio-protection of germinated seeds against soil borne pathogens and plant growth promotion (Goudjal et al., 2014).

\section{Volatile antibiotics}

The actinomycetes especially the genus Streptomyces have been reported to produce volatile antifungal substances which inhibit the growth of plant pathogens by causing morphological abnormalities like inhibition of spore and conidial germination, appressorial formation etc. in fungi such as Aspergillus sp., Magnaporthe oryzae, Trichoderma viride and F. oxysporum (Herrington et al., 1987). GCMS analysis of culture filtrate of Streptomyces alboflavus revealed 27 different compounds, among which dimethyl disulfide was proved to have inhibitory effect against $F$. moniliforme in vitro (Wang et al., 2013).

\section{Cell wall degrading enzymes}

Biocontrol agents produce hydrolytic enzymes which degrade fungal and bacterial cell wall, cell membrane, membrane proteins and extracellular virulence factors in controlling the plant diseases (Pal and Gardener, 2006). Abd-Allah (2001) had reported production of chitinase by endophytic actinomycetes as a biocontrol trait. In this study, 372 strains were screened for the production of this enzyme 
and and isolate Streptomyces plicatus was found better. Chitinase from Streptomyces plicatus had a significant inhibition for Fusarium oxysporum f.sp. lycopersici and Verticillium albo-atrum. Streptomyces plicatus found affecting spore germination, germ tube elongation and radial growth of wilt pathogens of tomato and protected the plants in vivo when applied to the root system of tomato plants before transplantation.

Endophytic actinomycetes have been studied in many plants species. Streptomyces sp. is the most extensively studied organisms in actinomycetes for the production of cell walldegrading extracellular enzymes, their expression, substrate recognition and their involvement in growth and development (Charter et al., 2010). Among cell wall degrading enzymes, the chitinolytic enzyme plays a vital role in exhibiting antagonism by degrading the chitin, which is a major structural component of cell wall. The other extracellular enzymes are $\beta$-1,3-glucosidase, cellulose and protease which are also causing the lysis of hyphae and inhibit the growth of phytopathogens (Xue et al., 2013). Actinobacteria produces chitinases which is their main action against fungal pathogens (Yandigeri et al., 2015).The extracellular antifungal metabolites especially chitinase and $\beta-1,3$ glucanase produced by actinomycetes inhibit the growth of fungi through hyphal swelling, abnormal shapes and lysis of cell walls in $F$. oxysporum and $S$. rolfsii (Prapagdee et al., 2008; El-Katatny et al., 2001).

\section{Induction of host resistance}

Plants exhibit its own defense mechanism that provides resistance against diverse plant pathogens. This defense mechanism is of two types: induced systemic resistance (ISR) and systemic acquired resistance (SAR). The ISR mechanism is induced by the rhizobacteria and SAR is induced by pathogen and salicylic acid (Schuhegger et al., 2006). Conn et al., (2008) reported that the endophytic actinomycetes were able to induce the SAR and jasmonic acid (JA) / ethylene (ET) pathways which gave the resistance against the fungal pathogen, $F$. oxysporum and bacterial pathogen, Erwinia carotovora subsp. carotovora, respectively. The culture filtrate of an endophytic Micromonospora sp. strain EN43, Sreptomyces sp. strain EN27 against $E$. carotovora ssp. carotovora in Arabidiopsis thaliana, Streptomyces bikiniensis HD-087 against $F$. oxysporum f.sp. cucumerinum in cucumer and Streptomyces sp. GB4-2 against Botrytis cinerea in Norway spruce induced the SAR and JA/ET pathways (Conn et al., 2008; Lehr et al., 2008; Zhao et al., 2012). Dual-culture assay is the most commonly used method for evaluating the antagonistic activity of organisms against plant pathogenic fungi in vitro (Khamna et al., 2009; Baz et al., 2012). Actinomycetes has been reported to exhibit antagonistic activity against Erwinia carotovora subsp. carotovaora and Burkholderia cepacia in biological control of onion rot (Abdallah et al., 2013), Streptomyces avidinii vh32, S. toxybicini vh22 and $S$. tricolor vh85 showed prominent antagonistic potential against Rhizoctonia solani and induced the accumulation of phenolic compounds in tomato (Patil et al., 2011) particularly gallic, ferulic, cinnamic, genteisic, chlorogenic and salicylic acids by which the bioagents immunize the plants against biotic stresses (Jones and Dangal, 2006). In the recent times, host plant resistance induced by Streptomyces had been studied on various crops including vegetables, forages and economically important woody plants like potato (Arseneault et al., 2014), eucalyptus (Salla et al., 2016) and oak (Kurth et al., 2014).

In conclusion, actinomycetes have a great potential to be utilized in the bioinoculant 
industry apart from its use in pharmaceuticals. It can enhance the plant growth by producing growth regulators and other compounds and it is well known for production of antibiotics which add to its quality as biocontrol agent. Other features like production of cell wall degrading enzymes and induced systemic resistance can also be useful in targeting new plant pathogens and will add to the campaign of green and sustainable agriculture. Many novel compounds can act as boon in problem of developing resistance among agro-pests. At the last, a much larger effort is being needed in future to explore the ocean of potential of actinomycetes.

\section{References}

Abd-Allah E.F. (2001). Streptomyces plicatus as a model biocontrol agent. Folia Microbiologica 46(4):309-314.

Abdallah M.E., Haroun S.A., Gomah A.A., El-Naggar N.E. and Badr H.H. (2013). Application of actinomycetes as biocontrol agents in the management of onion bacterial rot diseases. Archives of Phytopathology and Plant Protection 46(15): 1797-1808.

Abdel-Fattah G.M. and Mohamedin A.H. (2000). Interactions between a vesiculararbuscular mycorrhizal fungus (Glomus intraradices) and Streptomyces coelicolor and their effects on sorghum plants grown in soil amended with chitin of brawn scales. Biology and Fertility of Soils 32(5): 401-409.

Arseneault T, Pieterse C. M., Gerin-Ouellet M., Goyer C., Filion M. (2014). Long term induction of defense gene expression in potato by Pseudomonas sp LBUM223 and Streptomyces scabies. Phytopathology, 104: 926-932.

Bakkar P.A.H.M. Pieterse C.M.J and Van Loon L.C. (2007). Induced systemic resistance by fluorescent Pseudomonas spp. Phytopathology 97: 239-243.
Baz M., Lahbabi, D., Samri S., Val F., Hamelin G., Madore I., Bouarab K., Beauliew C., Ennaji M. and Barakate M. (2012). Control of potato soft rot caused by Pectobacterium carotovorum and Pectobacterium atrosepticum byt Moroccan actinobacteria isolates. World Journal of Microbiology and Biotechnology 28: 303-311.

Cakmakci R., Donmez F., Aydin A. and Sahin F. (2006). Growth promotion of plants by plant growth-promoting rhizobacteria under greenhouse and two different field soil conditions. Soil Biology and Biochemistry 38: 14821487.

Cao L., Qiu Z., You J., Tan H. and Zhou S. (2004). Isolation and characterization of endophytic Streptomyces strains from surface-sterilized tomato (Lycopersicon esculentum) roots. Letters in Applied Microbiology 39: 425-430.

Charter, K.F., Biro, S., Lee, K.J. Palmer, T. and Schrempf, H. (2010). The complex extracellular biology of Streptomyces. FEMS Micobiology Reviews 34(2): 171198.

Conn V.M., Walker A.R. and Franco C.M.M. (2008). Endophytic actinobacteria induce defense pathways in Arabidiopsis thaliana. Molecular Plant-Microbe Interactions 21: 208-218.

Dhanasekaran D., Sivamani P., Pannerselvam A., Thajuddin N., Rajakumar G. and Selvamani S. (2005). Biological control of tomato seedling damping off with Streptomyces sp. Plant Pathology Journal 4: 91-95.

El-Katatny M.H., Gudelj M., Robra K.H., Elnaghy M.A. and Gubitz G.M. (2001). Characterization of a chitinase and an endo- $\beta-1,3$, glucanase from Trichoderma harzianum rifai $\mathrm{T} 24$ involved in the control of the phytopathogen sclerotium rolfsii. Applied Microbiology and 
Biotechnology 56: 137-143.

El-Tarabily K.A. and Sivasithamparam K. (2006).

Non-Streptomycete actinomycetes as biocontrol agent of soil-borne fungal pathogens and as plant growth promoters. Soil Biology and Biochemistry 38: 1505-1520.

El-Tarabily K.A., Nassar A.H., Hardy G. and Sivasithamparam K. (2009). Plant growth promotion and biological control of Pythium aphanidermatum, a pathogen of cucumber, by endophytic actinomycetes. Journal of Applied Microbiology 107: 672-681.

Franco-Correa M., Quintana A., Duque C., Suarez C., Rodríguez M.X. and Barea J.M. (2010). Evaluation of actinomycetes strains for key traits related with plant growth promotion and mycorrhiza helping activities. Applied Soil Ecology 45: 209-217.

Frey-Klett P., Garbaye J. and Tarkka M. (2007). The mycorrhiza helper bacteria revisited. New Phytologist 176(1): 2236.

Garbaye J. (1994). Heler bacteria: a new dimension to the mycorrhizal symbiosis. New Phytologist 128(2): 197-210.

Gopalakrishnan S., Pande S., Sharma M., Humayun P., Kiran B.K., Sandeep D., Vidya M.S., Deepti K. and Rupela O. (2011). Evaluation of actinomycete isolates obtained from herbal vermicompost for biological control of Fusarium wilt of chickpea. Crop Protection 30: 1070-1078.

Gopalakrishnan S., Srinivas V., Vidya M.S. and Rathore A. (2013). Plant growth promoting activities of Streptomyces spp. in sorghum and rice. Springer Plus 2: 574

Gopalakrishnan S., Vadlamudi S., Alekhya G., Prakash B., Kudapa H. and Varshney R.K. (2015). Evaluation of Streptomyces spp. Obtained from herbal vermicompost for broad spectrum of plant growth promoting activities in Chickpea. Organic Agriculture. 5:123133.

Goudjal Y., Toumatia O., Yekkour A., Sabaou N., Mathieu F. and Zitouni A. (2014). Biocontrol of Rhizoctonia solani damping off and promotion of tomato plant growh by endophytic actinomycetes isolated form native plants of Algerian Sahara. Microbiological Research 169(1): 5965.

Gregor, A.K., Klubek, B. and Varsa, E.C. (2003). Identification and use of actinomycetes for enhanced nodulation of soybean co-inoculated with Bradyrhizobium japonicum. Canadian Journal of Microbiology. 49:483-491.

Hamdali H., Bouizgarne B., Hafidi M., Lebrihi A., Virolle M.J. and Ouhdouch Y. (2008). Screening for rock phosphate-solubilizing Actinomycetes from Moroccan phosphate mines. Applied Soil Ecology 38: 12-19.

Hamdali, H., Smirnov, A., Esnault, C., Ouhdouch, Y. and Virolle, M.J. (2010). Physiological studies and comparative analysis of rock phosphate solubilization abilities of Actinomycetales originating from Moroccan phosphate mines and of Streptomyces lividans. Applied Soil Ecololgy 44:24-31.

Herrington P.R., Craig J.T. and Sheridan J.E. (1987). Methyl vinyl ketone: a volatile fungistatic inhibitor from Streptomyces griseoruber. Soil Biology and Biochemistry 19(5): 509-512.

Hoster F., Schmitz J.E. and Daniel R. (2005). Enrichment of chitinolytic microorganisms: isolation and characterization of chitinase exhibiting antifungical activity against phytopathogeneic fungi from a novel Streptomyces strain. Applied Microbiology and Biotechnology, 66: 434-442. 
Hyang B.L., Hack S.J., Lee H.B., Kim Y., Choi G.J., Park S.H., Kim C.J. and Jung H.S. (2005). Activity of some aminoglycoside antibiotics against true fungi, Phytophthora and Pythium species. Journal of Applied Mirobiology 99: 836-843.

Jinhua C., Yang S.H., Palaniyandi S.A., Han J.S., Yoon T.M., Kim T.J. and Suh J.W. (2010). Azalomycin F complex is an antifungal substance produced by Streptomyces malaysiensis MJM1968 isolated from agricultural soil. Journal of the Korean Society for Applied Biological Chemistry 53(5): 545-552.

Jog, R., Pandhya, M., Nareshkumar, G and Rajkumar, S. (2014). Mechanism of phosphate solubilization and antifungal activity of Streptomyces spp. isolated from wheat roots and rhizosphere and their application in improving plant growth. Microbiology. 160:778-788.

Jones J.D.G. and Dangl J.L. (2006). The Plant Immune System. Nature Reviews 444: 323-329.

Kavitha A., Prabhakar P., Narasimhulu M., Vijayalakshmi M., Venkateswarlu Y., Venkateswara Rao K. and Subba Raju V.B. (2010). Isolation, characterization and biological evaluation of bioactive metabolites from Nocardia levis MKVL_113. Microbiological Research 165: 199-210.

Khamna S., Yokota A. and Lumyong S. (2009). Actinomycetes isolated from medicinal plant rhizosphere soils: diversity and screening of antifungal compounds, indole-3-acetic acid and siderophore production. World Journal of Microbiology and Biotechnology 25: 649-655.

Kurth F., Mailander S., Bonn M., Feldhahn L, Herrmann S, Große I., Buscot F., Schrey, S.D and Tarkka M.T. (2014). Streptomyces induced resistance against oak powdery mildew involves host plant responses in defense, photosynthesis, and secondary metabolism pathways. Molecular plant Microbe Interaction. 27: 891-900

Lehman, L.J., Randy, J.M., Caiyao, Y., Denise, M.C., Orjala, J.C., Marrone, P.G. and Satamaia, J.L.J. (2005). Metabolites from Streptomyces strain NRRL accession No. B-30145 and mutants thereof for controlling plant diseases. US Patent 6, 852.317

Lehr N.A., Schrey S.D., Hampp R. and Tarkka M.T. (2008). Root inoculation with a forest soil Streptomycetes leads to locally and systemically increased resistance against phytopathogens in Norway spruce. New Phytologist 177(4): 965-976.

Liu X., Bolla K., Ashforth E.J., Zhuo Y., Gao H., Huang P., Stanley S.A., Hung D.T. and Zhang L. (2012). Systematic-guided bioprospecting for bioactive natural products. Antonie van Leeuwenhoek 101: 55-66.

Lu C.G., Liu W.C., Qiu J.Y., Wang H.M., Liu T. and Liu D.W. (2008). Identification of an antifungal metabolite produced by a potential biocontrol Actinomyces strain A01. Brazilian Journal of Microbiology 39: 701-707.

Nassar A.H., El-Tarabily K.A. and Sivasithamparam K. (2003). Growth promotion of bean (Phaseolus vulgaris L.) by a polyamine-producing isolate of Streptomyces griseoluteus. Plant Growth Promotion, 40: 97-106.

Nimnoi P., Pongsilp N. and Lumyong S. (2010). Endophytic actinomycetes isolated from Aquilaria crassna Pierre ex Lec and screening of plant growth promoters production. World Journal of Microbiology and Biotechnology 26(2): 193-203.

Pal K.K. and Gardener B.M. (2006). Biological control of plant pathogens. The Plant Health Instructor doi: 
10.1094/PHI-A-2006-1117-02.

Palaniyandi S.A., Yang S.H., Cheng J.H., Meng L. and Suh J.W. (2011). Biological control of anthracnose (Colletotrichum gloeosporioides) in yam by Streptomyces sp. MJM5763. Journal of Applied Microbiology 111: 443-455.

Patil H.J., Srivastava A.K., Singh D.P., Chaudhari B.L. and Arora D.K. (2011). Actinomycetes mediated biochemical responses in tomato (Solanum lycopersicum) enhances bioprotection against Rhizoctonia solani. Crop Protection 30: 1269-1273.

Pattanapipitsai P. and Kamlandharn R. (2012). Screeening of chitinolytic actinomycetes for biological control of Sclerotium rolfsii stem rot disease of chilli. Songklanakarin Journal of Science and Technology 34(4): 387-393.

Prapagdee B., Kuekulvong C. and Mongkolsuk S. (2008). Antifungal potential of extracellular metabolites produced by Streptomyces hygroscopicus against phytopathogenic fungi. International Journal of Biological Sciences 4: 330-337.

Sabaratnam S. and Traquair J.A. (2002). Formulation of a Streptomyces biocontrol agent for the suppression of Rhizoctonia damping-off in tomato transplants. Biological Control 23: 245253.

Salla T.D., Astarita L.V., Santarem E.R. (2016). Defense responses in plants of eucalyptus elicited by Streptomyces and challenged with Botrytis cinerea. Planta. 243:1055-1070

Schrey S.D., Schellhammer M., Ecke M., Hampp M. and Tarkka M.T. (2005). Mycorrhiza helper bacterium Streptomyces AcH 505 induces differential gene expression in the ectomycorrhizal fungus Amanita muscaria. New Phytologist 168:205-216

Schuhegger R., Nafisi M., Mansourova M.,
Petersen B.L., Olsen C.E., Svatos A., Halkier B.A., and Glawischnig, E. (2006). CYP71B15 (PAD3) catalyzes the final step in camalexin biosynthesis. Plant Physiol. 141 1248-1254.

Shigaki F., Sharpley A.N. and Prochnow L.I. (2006). Animal-based agriculture, phosphorus and management and water quality in Brazil: options for the future. Scientia Agricola 63: 194-209.

Shimizu M., Nakagawa Y., Sato Y., Furumai T., Igarashi Y., Onaka H., Yoshida R. and Kunoh H. (2000). Studies on Endophytic Actinomycetes (I) Streptomyces sp. Isolated from Rhododendron and Its Antifungal Activity. Journal of General Plant Pathology 66(4): 360-366.

Soe, K.M and Yamakawa, T. (2013).Evaluation of effective Myanmar Bradyrhizobium strains isolated from Myanmar soybean and effects of co-inoculation with Streptomyces griseoflavus $\mathrm{P} 4$ for nitrogen fixation. Soil Scice and Plant Nutrition. 59:361-370.

Solans, M., Vobis, G. and Wall, L. G. (2009). Saprophytic actinomycetes promote nodulation in Medicago sativaSinorhizobium meliloti symbiosis in the presence of high N. Journal of Plant Growth Regulation. 28:106-114.

Solans, M., Ruiz, O.A, and Wall, L.G.(2015). Effect of actinobacteria on Lotus tenuisMesorhizobium loti symbiosis: preliminary study. Symbiosis 65:33-37.

Sreevidya, M., Gopalakrishnan, S., Kudapa, $\mathrm{H}$ and Varshney, R.K. 2016. Exploring plant growth promotion actinomycetes from vermicompost and Rhizosphere soil for yield enhancement in chickpea. Brazilian Journal of Microbiology, 47(1): 85-95

Tan H.M., Cao L.X., He Z.F., Su G.J., Lin B. and Zhou S.N. (2006). Isolation of Endophytic Actinomycetes from 
Different Cultivars of Tomato and their Activities Against Ralstonia solanacearum in Vitro. World Journal of Microbiology and Biotechnology 22(12): 1275-1280.

Tian X.L., Cao L.X., Tan H.M., Zeng Q.G., Jia Y.Y., Han W.Q. and Zhou S.N. (2004). Study on the communities of endophytic fungi and endophytic actinomycetes from rice and their antipathogenic activities in vitro. World Journal of Microbiology and Biotechnology 20(3): 303-309.

Trejo-Estrada S.R., Sepulveda I.R. and Crawford D.L. (1998). In vitro and In vivo antagonism of Streptomyces violaceunsniger YCED9 against fungal pathogen of turf grass. World Journal of Microbiology and Biotechnology 21: 8190.

Verma V.C., Gond S.K., Anuj Kumar, Mishra A., Kharwar R.N. and Gange A.C. (2009). Endophytic Actinomycetes from Azadirachta indica A. Juss.: Isolation, Diversity, and Anti-microbial Activity. Microbial Ecology 57(4): 749756.

Vijayabharathi R., Sathya A and Gopalakrishnan S. (2016). A renaissance in plant growth promoting and biocontrol agents by endophytes. In: Singh D.P., Singh H.D., Prabha R (Eds.) Microbial inoculants in sustainable agricultural productivity. Springer, India, pp 37-61.

Wang C., Wang Z., Qiao X., Li Z., Li F., Chen M., Wang Y., Huang Y. and Cui
H. (2013). Antifungal activity of volatile organic compounds from Streptomyces alboflavus TD-1. FEMS Microbiology Letters 341(1): 45-51.

Xue L., Xue Q., Chen Q., Lin C., Shen G. and Zhao J. (2013). Isolation and evaluation of rhizosphere actinomycetes with potential application for biocontrol of Verticillium wilt of cotton. Crop Protection 43: 231-240.

Yandigeri, M.S., Malviya, N., Solanki,M.K., Shrivastava, P. and Sivakumar, G. (2015). Chitinolytic Streptomyces vinaceusdrappus S5MW2 isolated from Chilika lake, India enhances plant growth and bio-control efficacy through chitin supplementation against Rhizoctonia solani. World Journal of Microbiology and Biotechnology. 31:1217-1225.

Zhao K., Penttinen P., Guan T., Xiao J., Chen Q., Xu J., Lindström K., Zhang L., Zhang X and Strobel G. A (2011). The Diversity and Anti-Microbial Activity of Endophytic Actinomycetes Isolated from Medicinal Plants in Panxi Plateau, China. Current Microbiology 62(1): 182-190.

Zhao S., Du C.M. and Tian C.Y. (2012). Suppression of Fusarium oxysporum and induced resistance of plants involved in the biocontrol of cucumber Fusarium wilt by Streptomyces bikiniensis HD-087. World Journal of Microbiology and Biotechnology 28(9): 2919-2927.

\section{How to cite this article:}

Nanjappan Karthikeyan, Kuppusamy Pandiyan, Pramod Kumar Sahu, Ramakrishnan Srinivasan, Udai B. Singh. 2018. Actinomycetes: A Promising Tool for Plant Growth Promotion and Disease Control. Int.J.Curr.Microbiol.App.Sci. 7(07): 2418-2429. doi: https://doi.org/10.20546/ijcmas.2018.707.283 